FRANCISCO CAMPUZANO BOLARÍN, Ph.D.

E-mail: francisco.campuzano@upct.es

Technical University of Cartagena,

Department of Business Economics

ANTONIO GUILLAMÓN FRUTOS

E-mail: antonio.guillamon@upct.es

Technical University of Cartagena,

Department of Applied Mathematics and Statistics

Campus Muralla del Mar s/n, 30201 Cartagena, Spain

ANDREJ LISEC, Ph.D.

E-mail: andrej.lisec@fl.uni-mb.si

University of Maribor, Faculty of Logistics

Hočevarjev trg 1, SI - 8271 Krško, Slovenia
Distribution Logistics

Review

Accepted: Jan. 29, 2010

Approved: Mar. 8, 2011

\title{
ASSESSING THE IMPACT OF PRICES FLUCTUATION ON DEMAND DISTORTION WITHIN A MULTI-ECHELON SUPPLY CHAIN
}

\begin{abstract}
Price fluctuation is a practice commonly used by companies to stimulate demand and a main cause of the Bullwhip effect. Assuming a staggered step demand pattern that responds elastically to retailer's price fluctuation, and by using a supply chain management dynamic model, we will analyse the impact of these fluctuations on the variability of the orders placed along a traditional multilevel supply chain. Subsequently, the results obtained will serve to propose a forecasting model enabling to calculate the potential variability of orders placed by each echelon on the basis of the price pattern used. Finally, under the hypothesis of an environment of collaboration between the different members of the chain, we propose a predictive model that makes it possible to quantify the distortion of the orders generated by each level.
\end{abstract}

\section{KEYWORDS}

Bullwhip effect, systems dynamics, price fluctuation, supply chain management

\section{INTRODUCTION}

Companies nowadays are confronted with many challenges. Growing competitiveness and globalization require from companies more and more efficient responses and solutions (processes and strategies) that enable them to interact in a continuously changing world, where customers increasingly hold bargaining power and, at the end, determine the success or failure of the whole business mechanism which underlies the manufacturing of a product. This scenario becomes even more complex, considering that the production and marketing work do not finish at the moment of the sales; only after the client has accepted, is entirely satisfied with the product, and has paid; all this forward manufacturing flow has fulfilled its mission, regardless from the closed-loop or reverse supply chain model.

Adequate Supply Chain Management is crucial for companies to remain competitive. Currently, competition is not only among companies but also among supply chains; new management tools (based on IT), are fostering the integration of companies in supply chains and the emergence of entities capable of responding more efficiently, Vaculik et al. [1]. Nevertheless, some underlying issues should be resolved to achieve efficient operation of a Supply Chain.

When Forrester [2] analysed a Traditional Supply Chain, he observed that a small variation in customer's demand pattern became amplified as it flowed through the production, supply and distribution processes. At each level of the chain this deviation became amplified upstream, in the form of replenishment orders. This effect is known as the Forrester Effect.

According to Forrester, the amplification was due to problems arising from non-zero lead times and inaccurate forecasting by each member of the chain regarding the demand variability. Some decades later, Lee et al. [3] identified that demand distortion relative to sales caused by the Forrester effect became even more amplified because of some or all of the following factors, which can be simultaneously present in the Supply Chain: order batching, product price fluctuations, rationing and shortage of finished products. This distortion in replenishment orders of products relative 
to end customer's demand resulting from the combination of the mentioned elements (distortion which keeps on increasing as we move from end customer along the supply chain), is called the Bullwhip effect.

The study of the Bullwhip effect has given rise to numerous works, aimed at both analysing its causes and solving it by means of various management strategies. All these contributions can be classified as follows:

- Studies focused on how to reduce the Bullwhip effect, which put forward the smoothing of replenishment orders or new collaborative structures for information exchange among the supply chain members. The works of Deziel and Elion [4], Sterman [5], John et al. [6], Lee et al. [7], Kelle and Milne [8], Lee et al. [9], Disney and Towill [10, 11], Disney et al. [12], Dejonckheere et al. [13] are worth mentioning.

- Works focused on analysing the impact of several factors on the Bullwhip effect, such as variable lead times, inaccuracy of forecasts and lack of information among the members of the chain. In this respect, the studies by Chen et al. [14], Lee et al. [7], Metters [15], So and Zheng [16], Chatfield et al. [17], Hosoda and Disney [18] are the most outstanding ones.

Many of these authors' analytical models provide satisfactory results, although some methodological difficulties could arise from the structure of the models developed when it comes to applying them, as well as considerable constraints in their field of application, owing to some rigid conditions established, such as, for example, the fact that they concentrate only on one parameter [19]. It should also be noted that the article by Lee et al. [20] provides an excellent approach to the analysis of the causes and potential solutions of the Bullwhip effect.

As previously mentioned, price fluctuation is one the major causes of the appearance of Bullwhip effect in the supply chain. This practice is used by businessmen to stimulate the demand [21] to the extent that in many companies the budget allocated for sales promotion is higher than the budget allocated for advertising [22].

It is very common that wholesalers and manufacturers establish product pricing policies. Depending on each individual case, the manufacturer can offer discounts, usually by product volume, to encourage the wholesaler to purchase an amount larger that they need. If the difference between the real price of the item and the purchase price is bigger than the holding costs of the item, this strategy could prove profitable for the wholesaler in the first moment, but if they have not carried out a study to know what their real demand is, the holding costs could exceed the mentioned price difference and the expected benefits would not materialize [23]. Furthermore, it could also happen that the wholesaler goes on purchasing products until their warehouses are full. In that case, the wholesaler's actual demand information would not be reflected in their purchases to the manufacturer, with the subsequent appearance and/or magnification of the Bullwhip effect, since the size of the wholesaler's replenishment orders will bear no relation with the retailer's demand, thus leading to wrong forecasting upstream the supply chain. The wholesaler will just satisfy the demand by disposing of the stored products and this will distort the manufacturer's forecasts, which sees a sales decrease when compared to previous periods. These forecasts will prompt the manufacturer to reduce their production activity, and this might subsequently result in stock disruptions in their warehouse. The wholesaler can carry out such price policies for retailers and the latter for end-customers.

Price variation or modification by the members downstream the chain has been particularly studied by Özelkan et al. [24], who analyse the increase of this variation as we move downstream the supply chain, which becomes what the authors call "Reverse Bullwhip effect in Pricing" (RBP). This analysis complements the studies by Cowan [25] on the impact of changes in demand patterns on the sale prices within the different types of economies and, consequently, on the benefits these changes entail. For Özelkan et al. [15] price fluctuation can be the cause behind an increase of distortion in replenishment orders or, in other words, a magnification of the Bullwhip affects upstream the supply chain.

The present paper complements both authors' analysis, by studying the fluctuation of the retailer's prices, and its impact on the proper management of a traditional multilevel supply chain (made up of manufacturer, wholesaler, retailer and end customer). By using a staggered step demand pattern, which responds elastically to retailer price fluctuation, the paper will analyze the influence of these fluctuations in the variability of the orders placed along the modelled supply Chain, by means of the supply chain management dynamic model proposed by Campuzano et al. [26]. In order to quantify that distortion, we will calculate the Coefficient of Variation associated with each series (replenishment / manufacturing orders) and obtained from different simulations carried out with the dynamic model proposed, by using a seasonal price pattern disturbed by different variability levels. Finally, if we considered possible an environment of collaboration between the different members of the chain, we propose, using linear regression, predictive model techniques that enable quantification of the distortion of the orders generated using information about variability prices and orders at the level immediately downstream.

The Bullwhip effect appears as the replenishment/ manufacturing orders Coefficient of Variation increases upstream the supply chain. The measurement of 
the Bullwhip effect proposed by Chen et al. [14] has not been deemed appropriate in this case, because its sensitiveness to small values in demand might induce this indicator to produce wrong values (huge peaks) which distort that measurement. Furthermore, as this is a traditional multilevel supply chain, it is difficult for manufacturers or wholesalers to actually know what the final demand is. With the results obtained we will try to forecast the potential variation of the orders generated at each level, taking the price pattern as a starting point.

DPP (Discounts on the Purchase Price) have been profusely dealt with in the current specialized literature - within the field of Operations Management focusing (their research) on models in search of the optimal strategy for the retailer to follow when it comes to applying discounts on the end consumer purchase price, in order to avoid inventory problems and subsequent holding costs. The works by Arcelus et al. [27, 28,29 ] or Ardalan [30] are worth mentioning. Some of them use demand patterns sensitive to price fluctuations but they do not manage to simulate their effect along a multilevel supply chain as far as the Bullwhip effect is concerned.

The dynamic model used here includes the variables necessary to characterize the demand management process (inventory levels, replenishment orders, manufacturing, forecasts). This model takes into consideration the capacity constraints, management of backlogged orders, fill rate, measurement of the Bullwhip effect and inventory costs associated with each level, and it can be used to recreate different types of supply chain management strategies (different scenarios) in order to measure the impact of these strategies in the demand management process.

\section{METHODOLOGICAL APPROACH}

Systems Dynamics methodology is a modelling and simulation technique designed for studying problems associated, among others, with logistics, manufacturing management process, organizations or socioeconomics. The aims of the system dynamics are to examine the interaction of various functions (physical processes, information flows and management policies) within a system in order to obtain a better understanding, improve the interaction of components and integrate them into a meaningful whole, to design adequate mechanisms and decision rules. Therefore, the purpose of our model would not be to predict what the total supply chain profit level would be each week for the years to come, but to reveal under what conditions the total profit would be higher, if and when it would be negative, if and how it can be controlled [31].

The structure of a system in Systems Dynamics methodology is represented by causal loop diagrams. Causal loop diagrams consist of variables connected by arrows denoting the causal influences among the variables. These variables are related by causal links, shown by arrows. Each causal link is assigned a polarity, either positive (+) or negative (-) to indicate how the dependent variable changes when the independent variable changes.

A dynamic system model contains the stock (state of the system) and flow (rate) variables. Stocks are accumulations and can only be changed via flows. Mathematically, a stock can be seen as an accumulation or integration of flows over time - with outflows being subtracted from the stock. Stocks typically have a certain value at each moment of time - (i.e. inventories). Flow variables (or "rate") change the stock over time (i.e., order rate). Usually we can clearly distinguish inflows (adding to the stock) and outflows (subtracting from the stock). Flows are typically measured over a certain interval of time.

Stock and flow diagrams (Forrester diagrams) represent the model structure and the interrelationships among the variables. Stock and flow diagrams have a mathematical meaning. Stocks accumulate or integrate their flows; the net flow into the stock is the rate of change of the stock. In our case, the graphical simulation program used to support the analysis and study of the model created was Vensim (C) by Ventana Systems.

\section{PROBLEM AND MODEL CONSTRUCTION}

For this work we have used the model created to study the demand management process along a Traditional Supply Chain [26]. The main characteristics of this model are summarized in the following points:

- A four-stage supply chain system (multi-echelon supply chain) consisting of identical agents was considered, where each agent orders products only to its upper stage. These stages are: Customer, Retailer, Wholesaler and Manufacturer.

- An agent ships goods immediately upon receiving the order if there is sufficient amount of on-hand inventory. We are considering a "Pull" planning strategy.

- Orders may be partially fulfilled (every order to be delivered includes current demand and backlogged orders, if any), and unfulfilled orders are backlogged.

- Shipped goods arrive with a transit lead-time and they are also delayed because of information lead time.

- Last stage (manufacturer) receives raw materials from an infinite source and manufactures finished goods under capacity constraints. In this work, capacity constraints do not influence the size of manufacturing orders, since the manufacturing capacity was set high enough to prevent those constraints from having an impact on the proposed analysis. 
The variables used to create the Traditional Supply Chain causal diagram have been selected taking as reference the APIOBPCS model (Automatic Pipeline, Inventory and Order-based Production Control System) [6]. For a more precise and detailed explanation and validation of the construction of the model we refer to Campuzano et al. [32]. However, a brief resume of the variables used for that purpose is set out below:

a) End customer demand and demand from one level towards the level situated immediately upstream. (See point 4.2);

b) Firm orders (for Retailer, Wholesaler and Manufacturer);

c) Backlogged orders (for Retailer, Wholesaler and Manufacturer);

d) The on-hand inventory (for Retailer, Wholesaler and Manufacturer);

e) Demand Forecasting (for Retailer, Wholesaler and Manufacturer). The forecast has been made using exponential smoothing forecasting;

f) Inventory Position (for Retailer, Wholesaler and Manufacturer): the inventory position is defined by the following relation:

Inventory position = inventory on hand + + orders placed but not yet received (or on-order products) - backlogged orders [33]; g) Replenishment orders (both for Retailer and Wholesaler);

h) Orders to the Manufacturer (Manufacturer level). Both replenishment and manufacturing orders to be made according to the inventory policy chosen to manage the demand. Regardless of the policy followed, the variables Demand Forecasting, Inventory Position and Supply or Manufacturing lead times will be taken into account to trigger these orders. The ordering policy we have chosen for our analysis is a generalized Order-Up-To policy [33]. In any order-up-to policy, ordering decisions are as follows:

$\mathrm{O}_{t}=\mathrm{S}_{t}$ - inventory position

The order quantity is equal to $S_{t}$, reduced for inventory position as:

\section{Inventory position= inventory on} hand-backlogged orders +

+orders placed but not yet received.

Where $O_{t}$ is the ordering decision made at the end of period $t, S_{t}$ is the order-up-to level used in period $t$ and the inventory position equals net stock plus on order (orders placed but not yet received), and net stock equals inventory on hand minus backlog. The order-up-to level is updated every period according to:

$S_{t}=\hat{D}_{t}^{L}+k \hat{\sigma}_{t}^{L}$

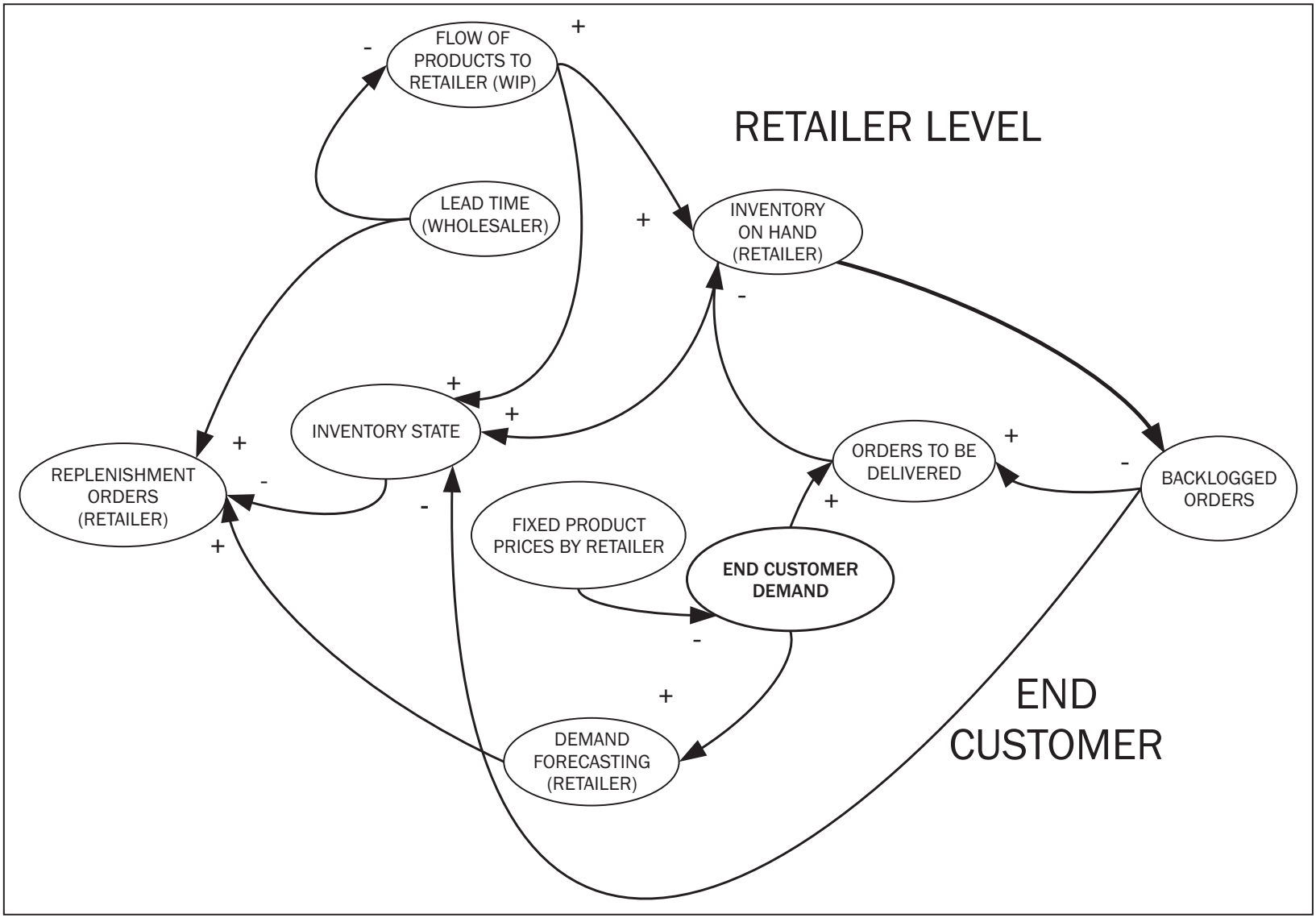

Figure 1 - The causal loop of a Traditional Supply Chain 
where $S_{t}$ is equal to the estimate mean of demand $\hat{D}_{t}^{L}$ over $L$ periods $\left(\hat{D}_{t}^{L}=\hat{D}_{t} \cdot L\right)$ increased for prescribed fill rate with buffer stocks, $\sigma_{t}^{L}$ is an estimation of the standard deviation over $L$ periods, and $k$ is the fill rate factor (safety factor) which depends on demand distribution.

i) Lead Time (both for Wholesaler and Manufacturer);

j) On-order products (for Retailer, Wholesaler and Manufacturer);

k) Manufacturing capacity (Manufacturer level);

I) Manufacturing (Manufacturer level);

m) Manufacturing lead time (Manufacturer level);

n) Fill rates (for Retailer, Wholesaler and Manufacturer);

o) Inventory costs (holding and order costs) (for Retailer, Wholesaler and Manufacturer);

p) Prices Pattern (See point 4.1).

Figure 1 shows a piece of the structure for a multiechelon supply chain system in its corresponding causal loop diagram.

\section{PRICE AND DEMAND PATTERNS}

\subsection{Price Pattern}

Price fluctuation is a practice frequently used at the moments of demand decrease either to stimulate it or when a production surplus or shortage occurs. A price

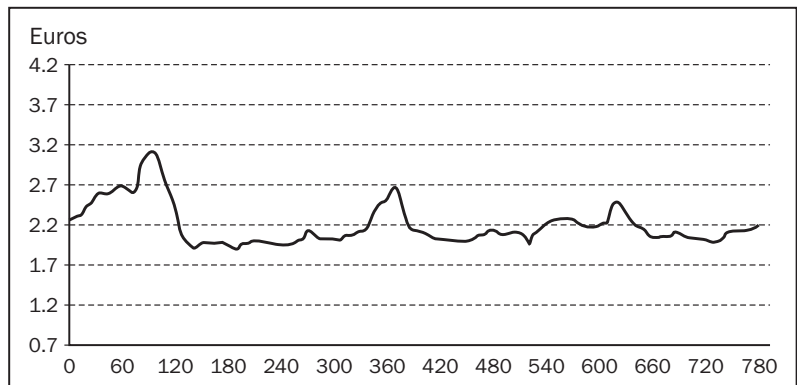

Figure 2 - Original price series

pattern with a seasonal component is very appropriate to modelling all these kinds of situations. Bearing in mind what has been set out above, a weekly price pattern with seasonal component has been taken for this study corresponding to 780 variations ( 3 years at a rate of 5 observations per week). This dataset corresponds to the final price of tomatoes during the years 2005, 2006 and 2007, (source: official WEB of Ministerio de Medioambiente, Rural y Marino, Spanish Government).

To analyse the impact of price fluctuation on replenishment/manufacturing orders at different levels of the modelled supply chain, a centred Gaussian perturbation was added to the original price series (mean equal to zero) with different variability levels. So, the series labelled as A1, A2 and A3 in Figure 3 show the results obtained when the original price series in Figure 2 is disturbed by a low variability signal (standard deviation $=0.15$ ). The series labelled as B1, B2 and B3

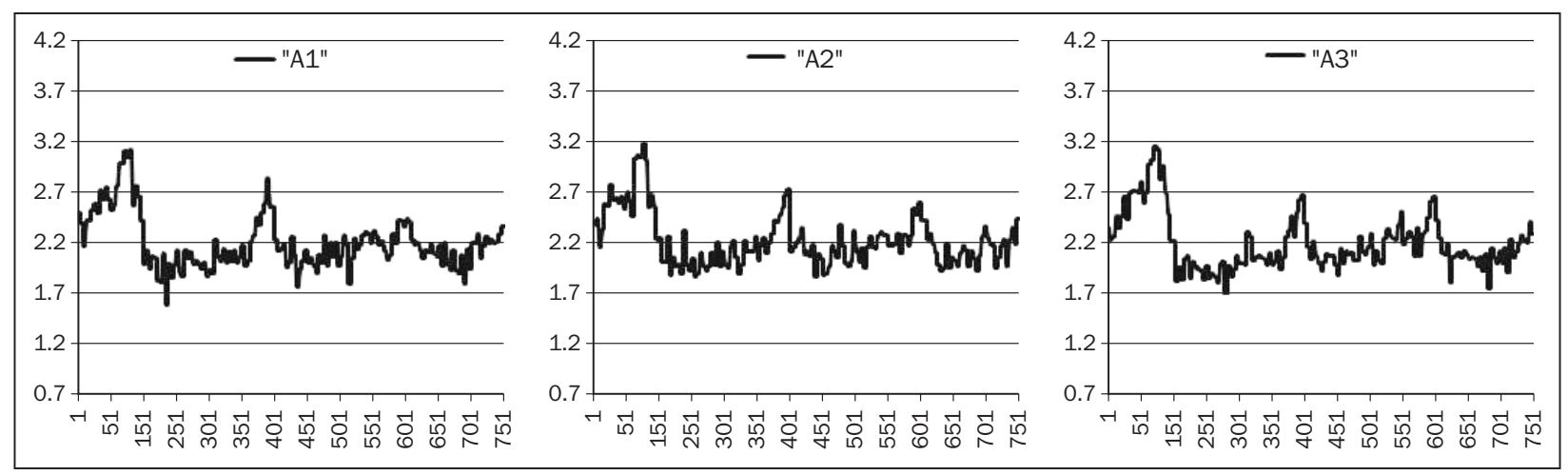

Figure 3 - Series disturbed by low variability
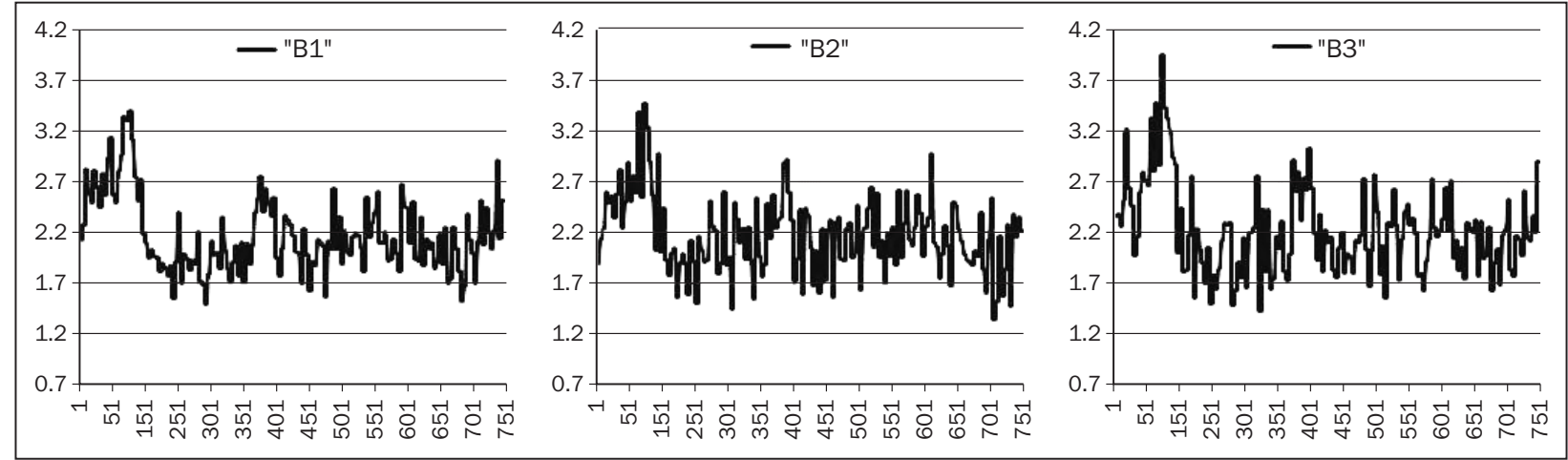

Figure 4 - Series disturbed by medium variability 

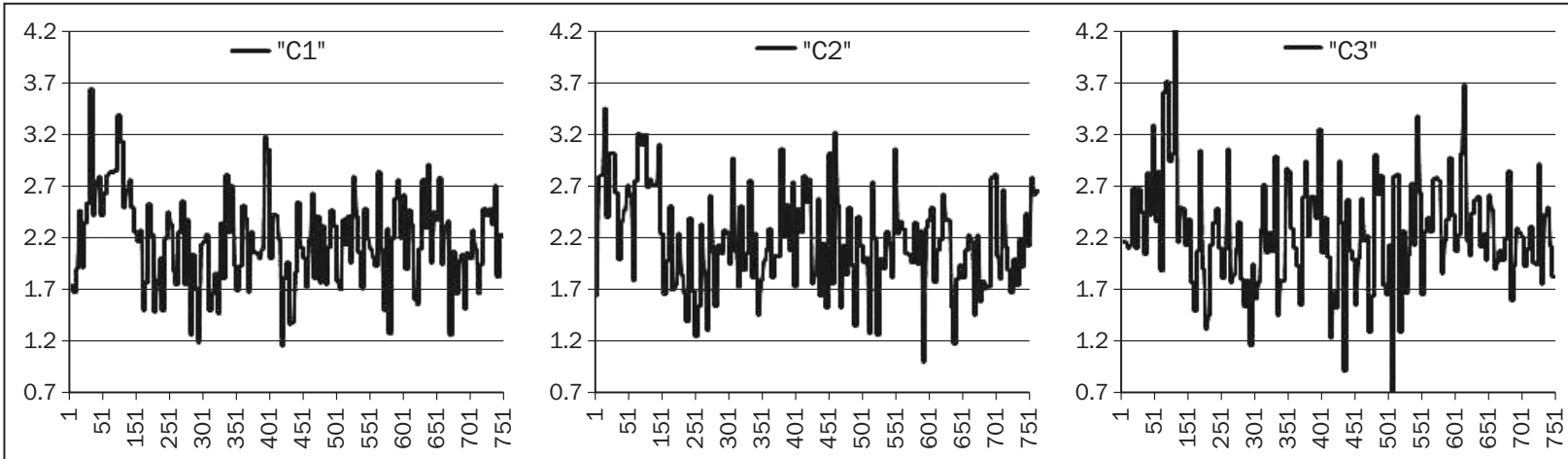

Figure 5 - Series disturbed by high variability

in Figure 4 show the results obtained when the original price series is disturbed by a medium variability signal (standard deviation $=0.25$ ), and the series labelled C1, C2 and C3 (Figure 5) show the price series obtained when the series is disturbed by a high variability signal (standard deviation $=0.40$ ).

\subsection{Demand Pattern}

The demand placed by the end customer of a supply chain is one of the variables that influence significantly the chain response to replenishment/manufacturing orders. The Bullwhip effect depends to a large extent on the demand forecasts made by each member of the chain. This paper completes the current bibliography by analysing also the impact of price variations on the end customer's demand. A seasonal price pattern can trigger a staggered step demand type because low prices will result in periods of great demand, whereas high prices will result in a restrained demand. These aspects have led to the use of a staggered step demand pattern which responds elastically to the retailer's price fluctuation (see Table 1), and which allows a more realistic analysis of the appearance of the Bullwhip effect along the multilevel supply chain.

Table 1 - Demand pattern

\begin{tabular}{|c|c||}
\hline Prices & Demand Values \\
\hline \hline$(0.5,1.5) €$ & Uniform $(47,53)$ units \\
\hline$[1.5,3.0) €$ & Uniform $(22,28)$ units \\
\hline$[3.0,4.8) €$ & Uniform $(3,7)$ units \\
\hline
\end{tabular}

\section{OTHER MODEL PARAMETERS}

The following parameters defining the characteristics of the modelled traditional supply chain have been used for the simulation of the proposed model:

- Initial inventory level for manufacturer and wholesaler levels: 100 units. Initial inventory level for retailer level: 30 units.

- Manufacturer capacity: 160 units per day
- Wholesaler's lead time: 2 days. Manufacturer's lead time: 2 days. These lead times are supposed to be constant for all orders received except in case of stock-out.

- Manufacturing time: 3 days

- Fill rate factor $\mathrm{K}$ for each level $=2$

- Forecast adjustment factor: $2 \alpha=0.5$

\subsection{First results after simulation of the proposed model}

The simulation was carried out over a period of 780 days, 3 years at a rate of 5 observations per week. In order to avoid the transitional state and stabilize the fluctuation of the variation coefficient of each price series used and orders generated, the results obtained for the first 260 data (first year) were disregarded in each modelled level, to subsequently work with the data obtained from that moment on (Figure 6). It is worth pointing out that, from that moment on (data 260 onwards) the fluctuations disappear and we obtain a clear tendency of the coefficient of variation in all situations studied.

Figures 7, 8 and 9 show the orders variability at different levels, increase is evident as we move upstream the supply chain.

Table 2 shows the maximum, minimum and average values obtained for the variation coefficients at each

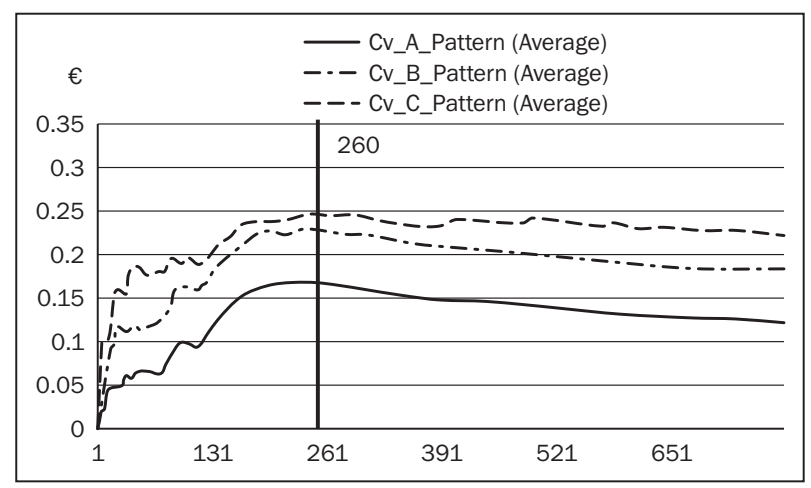

Figure 6 - Coefficient of Variation associated with the price patterns 


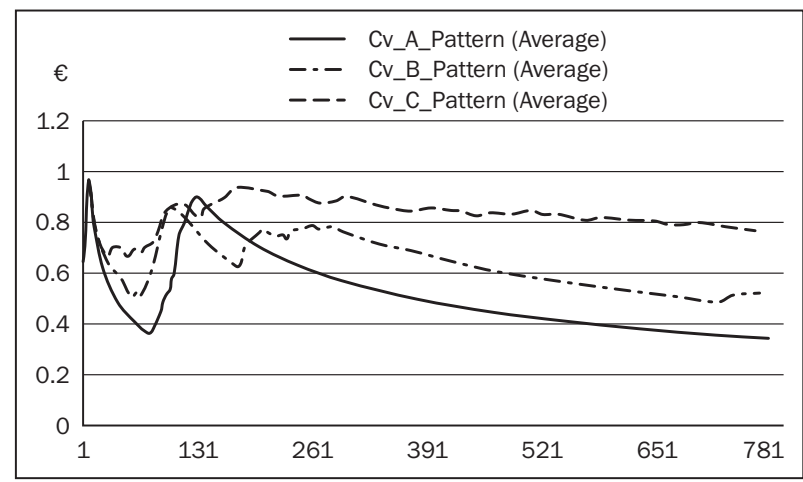

Figure 7 - Coefficient of Variation associated with retailer's orders

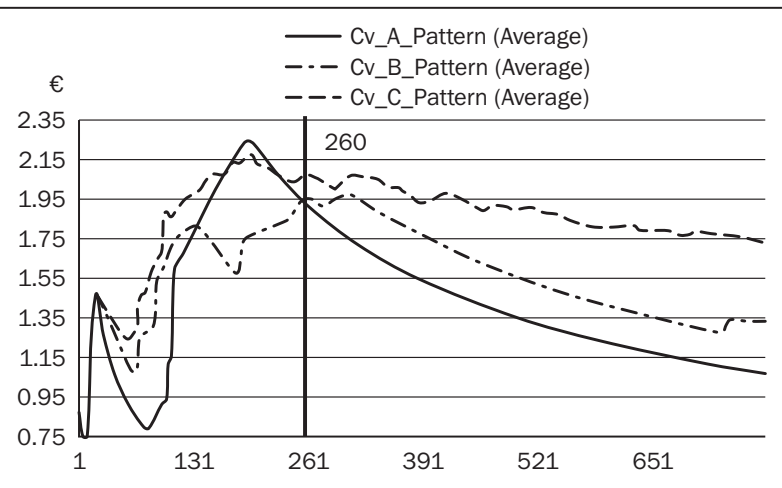

Figure 8 - Coefficient of Variation associated with wholesaler's orders

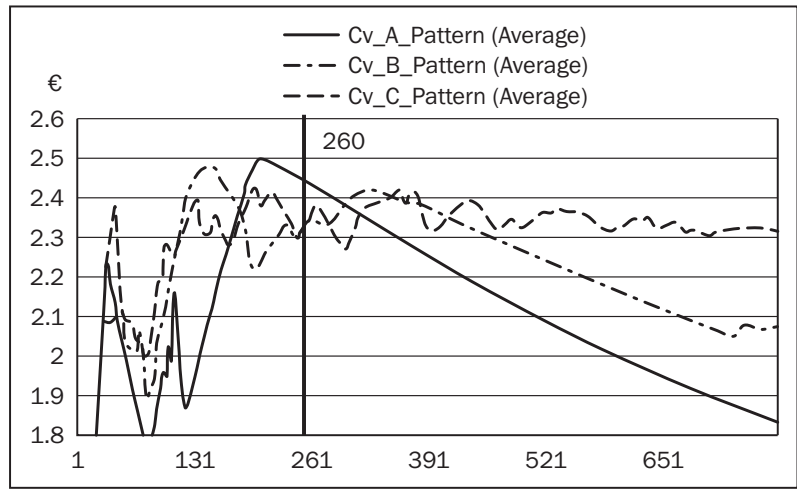

Figure 9 - Coefficient of Variation associated with manufacturing orders

level of the simulated chain. We denote the variation coefficients associated with each price series, and the replenishment/manufacturing series at different levels (retailer, wholesaler and manufacturer) by Cv_Prices, Cv_retailer, Cv_wholesaler and $\mathrm{Cv}$ _manufacturer.

The table shows a marked amplification in the variability of orders placed as we move upstream the supply chain. Thus, the wholesaler's average value of Coefficient of Variation is around 2.6 times that of the retailer, while the manufacturer's is 3.6 times that of the retailer and 1.4 times that of the wholesaler; all this reveals the appearance of the Bullwhip effect in the simulated chain, as well as the wholesaler's criti-
Table 2 - Range and average of the different coefficients of variation

\begin{tabular}{||l|c|c|c||}
\hline \hline & $\begin{array}{c}\text { Minimum } \\
\text { value }\end{array}$ & $\begin{array}{c}\text { Average } \\
\text { value }\end{array}$ & $\begin{array}{c}\text { Maximum } \\
\text { value }\end{array}$ \\
\hline \hline Cv_Prices & 0.11679 & 0.19019 & 0.26951 \\
\hline Cv_retailer & 0.33062 & 0.62160 & 0.96862 \\
\hline Cv_wholesaler & 1.0504 & 1.6114 & 2.1928 \\
\hline Cv_manufacturer & 1.8074 & 2.2270 & 2.4812 \\
\hline
\end{tabular}

cal position regarding demand fluctuations, much bigger than that of the manufacturer.

A positive correlation has been obtained between price variation and replenishment/manufacturing orders at each level; this dependence decreases as we move from one level to the level positioned immediately upstream (see Table 3).

Table 3 - Correlation among different coefficients of variation

\begin{tabular}{||l||c|c|c||}
\hline \hline & Cv_Prices & $\mathrm{C} v_{\text {_ }}$ retailer & $\begin{array}{c}\mathrm{Cv} \text { _whole- } \\
\text { saler }\end{array}$ \\
\hline \hline $\mathrm{C} v_{\text {_r retailer }}$ & 0.951 & & \\
\hline $\mathrm{Cv}$ _wholesaler & 0.837 & 0.931 & \\
\hline $\mathrm{C} v_{\text {_ manufacturer }}$ & 0.755 & 0.823 & 0.929 \\
\hline
\end{tabular}

Table 3 shows that the evolution of the variation coefficients at wholesaler and manufacturer levels cannot be predicted with any degree of certainty by only using the information on the fluctuation occurred in the price series, since these correlations are low.

\section{Establishment of a predictive model}

When it comes to building a predictive model that enables the quantification of the distortion of the orders generated by each level owing to the retailer's price fluctuation, linear regression models have been used, which were created assuming the retailer prices in each period are known by each chain level, that is, the retailer has information only on one price fluctuation, while the wholesaler has two information sources: price fluctuation and retailer's order variation, while the manufacturer - like the wholesaler - has information on price fluctuation and wholesaler's order variation.

Collaboration among the members of the chain is assumed, since the information on the prices offered to the end customer flows upstream from it. The EPOS (Electronic Point of Sales), structure, which, as several authors have already demonstrated, reduces the Bullwhip effect $[14,7]$, is similar to the one used in this work to build the predictive model, although in the EPOS structure the sales information to the end customer is passed on to each of the chain members, thus improving the forecasts made by them and reducing the variability of the generated replenishment/ manufacturing orders. 
Table 4 - T-test and F-test between Cv-retailer and Cv_prices

\begin{tabular}{|l||c|c|c|c||}
\hline \multicolumn{5}{|l|}{ T-test } \\
\hline \hline Predictor & Coef & SE Coef & T & P \\
\hline \hline Constant & -0.156354 & 0.003774 & -41.43 & 0 \\
\hline CV_Prices & 4.09047 & 0.01937 & 211.22 & 0 \\
\hline
\end{tabular}

\begin{tabular}{|c|c|c|c|c|}
\hline \multicolumn{5}{|c|}{ Analysis of Variance } \\
\hline Source & DF & SS & MS & $\mathrm{F}$ \\
\hline Regression & 1 & 141.4 & 141.4 & 44613.63 \\
\hline Residual Error & 4678 & 14.83 & 0 & \\
\hline Total & 4679 & 156.22 & & \\
\hline
\end{tabular}

Table 5 - T-test and F-test between $\mathrm{CV}$ wholesaler and Cv_prices, CV-retailer

\begin{tabular}{||l||c|c|c|c||}
\hline \multicolumn{1}{|l|}{ T-test } \\
\hline \hline Predictor & Coef & SE Coef & T & P \\
\hline \hline Constant & 0.863723 & 0.007597 & 113.7 & 0 \\
\hline CV_Prices & -3.6337 & 0.1082 & -33.57 & 0 \\
\hline Cv_retailer & 2.31453 & 0.02517 & 91.95 & 0 \\
\hline
\end{tabular}

\begin{tabular}{|l||r|r|r|r||}
\hline \multicolumn{4}{|l|}{ Analysis of Variance } \\
\hline \hline Source & DF & \multicolumn{1}{c|}{ SS } & \multicolumn{1}{c|}{ MS } & \multicolumn{1}{c|}{ F } \\
\hline \hline Regression & 2 & 367.03 & 183.51 & 19533.45 \\
\hline Residual Error & 4677 & 43.94 & 0.01 & \\
\hline Total & 4679 & 410.97 & & \\
\hline
\end{tabular}

Table 6 - T-test and F-test between $\mathrm{CV}$ manufactures and CV-wholesaler, CV_prices

\begin{tabular}{||l||c|c|r|c||}
\hline \multicolumn{1}{|l|}{ T-test } \\
\hline \hline Predictor & Coef & SE Coef & \multicolumn{1}{c|}{ T } & P \\
\hline \hline Constant & 1.38361 & 0.00495 & 279.48 & 0 \\
\hline CV_Prices & -0.28993 & 0.03845 & -7.54 & 0 \\
\hline CV_wholesaler & 0.557616 & 0.005513 & 101.14 & 0 \\
\hline \hline
\end{tabular}

\begin{tabular}{||l||r|r|r|c||}
\hline \multicolumn{5}{|l|}{ Analysis of Variance } \\
\hline \hline Source & DF & \multicolumn{1}{c|}{ SS } & MS & F \\
\hline \hline Regression & 2 & 112.554 & 56.277 & 15006.82 \\
\hline Residual Error & 4677 & 17.539 & 0.004 & \\
\hline Total & 4679 & 130.093 & & \\
\hline \hline
\end{tabular}

The predictive models obtained are given by the following expressions:

- Cv_retailer $=-0.156+4.09 C v \_$Prices $\left(R^{2}=0.905\right)$

- Cv_wholesaler $=0.864-3.63 C v \_$Prices +2.31 Cv_retailer $\left(R^{2}=0.893\right)$

- Cv_manufacturer $=1.38-0.290 C v \_$Prices + $+0.558 C v \_$wholesaler $\left(R^{2}=0.865\right)$

A model has been associated with each member of the simulated chain, enabling the calculation of the replenishment/manufacturing order variation which would be generated according to the information available. It is worth emphasizing the high reliability of the models obtained, since the determination coefficients obtained have been higher than 0.85 for each level.

Tables 4,5 and 6 show the results obtained by means of T-Test and F-test over the different regressions models proposed.

\section{CONCLUSION}

As expected, the model shows the appearance of the Bullwhip effect, resulting from a steep variability amplification of the orders generated as we move upstream in the supply chain. It also reveals the wholesaler's critical position in the face of demand fluctuations caused by price variations; this means the wholesaler's fill service will be consequently affected to a greater extent than the manufacturers'. This situation might be due to the fact that the wholesaler is confronted with several problems when it comes to generating replenishment orders to the manufacturer, such as: retailer order fluctuations caused by mistakes in forecasting and supply time, or the manufacturer's own supply times and forecast mistakes. This aspect should be taken into consideration when designing demand management policies (strategic level) in any multilevel supply chain.

On the other hand, Table 3 shows that price variation affects directly the increase of the variation of the orders placed by each chain level, but this effect becomes reduced at the wholesaler level and even more reduced at the manufacturer level.

As for our second objective, that is to say, the drawing up of a predictive model to quantify orders variation due to price fluctuations, we consider that orders variability cannot be predicted with enough reliability either at the wholesaler or at the manufacturer level if price evolution is the only available information. Nevertheless, the model developed in section 5.2 makes it possible to foresee, with a degree of reliability higher than $85 \%$, the evolution of each level's orders variability on the basis of price evolution and information coming from the level immediately downstream in the cases of wholesaler and manufacturer; that is to say, the wholesaler uses two sources of information - price fluctuation and retailer order variation - while the manufacturer, like the wholesaler, has information on price fluctuation and also on wholesaler order variation.

The expressions obtained in section 5.2 could allow the organization's strategic level to design demand management policies based on their records of product final prices and replenishment/manufacturing orders received. 


\section{Dr. FRANCISCO CAMPUZANO BOLARÍN}

E-mail: francisco.campuzano@upct.es

Universidad Politécnica de Cartagena, Departamento de Economía Financiera y Contabilidad

Dr. ANTONIO GUILLAMÓN FRUTOS

E-mail: antonio.guillamon@upct.es Universidad Politécnica de Cartagena, Departamento de Matemática Aplicada y Estadística

Campus Muralla del Mar s/n,

30201 Cartagena, España

Dr. ANDREJ LISEC

E-mail: andrej.lisec@fl.uni-mb.si

Univerza v Mariboru, Fakulteta za logistiko

Hočevarjev trg 1, 8271 Krško, Slovenija

\section{RESUMEN}

\section{EVALUACIÓN DEL IMPACTO DE LA FLUCTUACIÓN DE LOS PRECIOS EN LA DISTORSIÓN DE LA DEMANDA GENERADA EN UNA CADENA DE SUMINISTRO TRADICIONAL MULTINIVEL}

En este artículo se analiza la influencia de la fluctuacion de los precios en la variabilidad de las órdenes generadas a lo largo de una cadena de suministro tradicional multinivel. Para ello, se utiliza un modelo dinámico de gestión de cadena de suministro en el que se introduce un patrón de demanda tipo escalón, que responde elásticamente a la fluctuación de los precios ofrecidos por el minorista al cliente final. Posteriormente, utilizando los resultados obtenidos, se propone un modelo de previsión para calcular esa posible variación de las órdenes generadas en cada nivel, a partir del patrón de precios utilizado.

\section{PALABRAS CLAVE}

Efecto Bullwhip, Dinámica de Sistemas, Fluctuación de precios, Gestión de la cadena de suministro

\section{LITERATURE}

[1] Vaculik, J., Michalek, I., Kolarovszki, P.: Principles of se lection, implementation and utilization of RFID in supply chain management. Promet - Traffic\&Transportation, Vol. 21, No. 1, 2009, pp. 41-42

[2] Forrester, J.: Industrial Dynamics, A Major Breakthrough for Decision Makers. Harvard Business Review, July-August, 1958, pp. 67-96

[3] Lee, H.L., Padmanabhan, V., Whang, S.: The Bullwhip Effect in supply chains. Sloan Management Review 38 (3), 1997, pp. 93-102

[4] Deziel, D.P., Eilon, S.: A linear production-inventory control rule. The Production Engineer 43, 1967, 93 104

[5] Sterman, J.: Modelling managerial behavior: Misperceptions of feedback in a dynamic decision making experiment. Management Science, 35 (3), 1989, 321-339

[6] John, S., Naim, M.M., Towill, D.R.: Dynamic analysis of a WIP compensated decision support system. International Journal of Manufacturing Systems Design 1 (4), 1994, pp. 283-297
[7] Lee, H.L., Padmanabhan, P., Whang, S.: Information distortion in a supply chain: The bullwhip effect. Management Science 43, 1997a, pp. 543-558

[8] Kelle, P., Milne A.: The efect of (s, S) ordering policy on the supply chain. International Journal of Productions Economics, No. 59, 1999, pp. 113-122

[9] Lee, H.L., So, K.C., Tang, C.S.: The value of information sharing in a two-level supply chain. Management Science 46 (5), 2000, pp. 626-643

[10] Disney, S.M., Towill, D.R.: Vendor Managed Inventory and Bullwhip reduction in a Two level supply Chain. International Journal of Operations \& Production Management Vol. 23, No. 6, 2003, pp. 625-651

[11] Disney, S.M.; Towill D.R.: On the bullwhip and inventory variance produced by an ordering policy. The International Journal of Management Science, 2003a, pp. 157-167

[12] Disney, S. M., Naim M. M.; Potter, A. Potter: Assessing the impact of e-business on supply chain dynamics. International Journal of production economics. Vol. 89, 2004, pp. 109-118

[13] Dejonckheere, J., Disney, S.M., Lambrecht, M.R., TowiII, D.R.: The impact of information enrichment on the bullwhip effect in supply chains: A control engineering Perspective. European Journal of Operational Research, 153, 2004, pp. 727-750

[14] Chen, F., Drezner, Z., Ryan, J.K., Simchi-Levi, D.: Quantifying the bullwhip effect in a simple supply chain: The impact of forecasting, lead-times and information. Management Science 46 (3), 2000, 436-443

[15] Metters, R.: Quantifying the Bullwhip Effect in supply chains. Journal of Operations Management 15, 1997, pp. 89-100

[16] So, K.C., Zheng, X.: Impact of supplier's lead time and forecast demand updating on retailer's order quantity variability in a two level supply chain. International Journal of Production Economics, 86, 2003, pp. 169179

[17] Chatfield, D.C., Kim , J.G. Harrison T.P. Hayya, J.C.: The Bullwhip effect-Impact of Stochastic Lead Time, Information Quality, and Information Sharing, A simulation Study. Production and Operations Management, Vol. 13, No. 4, 2004, pp. 340-353

[18] Hosoda, T. and Disney S.M.: On variance amplification in a three-echelon supply chain with minimum mean square error forecasting. The international Journal of Management Science. Omega 34, 2005, pp. 344-358

[19] Swaminathan, Jayashankar M. and Tayur, Sridhar R.: Models for Supply Chains in E-Business. Management Science.Vol. 49, No. 10, 2003

[20] Lee HL, Padmanabhan V, Whang S.: Comments on "Information distortion in a supply chain: The bullwhip effect", The bullwhip effect: Reflections. Management Science 50 (12), 2004, pp. 1887-1993

[21] Neff, J.: Trade promotion rises. Advertising Age 71, 2000, pp. 24-8

[22] Blattberg, RC, Briesch, R.: Fox EJ. How promotions work. Marketing Science, 14, 1995, G122-32

[23] Mela CF, Jedidi K, Bowman D.: The long-term impact of promotions on consumer stockpiling behaviour. Journal of Marketing Research, 35, 1998, pp. 250-262 
[24] Özelkan, E.C., Çakanyıldırım, M.: Reverse Bullwhip Effect in Pricing, European Journal of Operational Research, 2007

[25] Cowan S.: Demand shifts and imperfect competition. University of Oxford, Department of Economics Discussion Paper Series, 2004, No. 188

[26] Campuzano Bolarín, F., Mcdonnel Ros, L., Lario Esteban, FC.: Bullwhip Effect Consequences according to Different Supply Chain Management Strategies: Modelling and Simulation. Journal of Quantitative Methods for Economics and Business Administration. Universidad Pablo de Olavide(Spain). Vol. V, 2008a, pp. 49-66

[27] Arcelus, FJ, Srinivasan, G.: Discount strategies for onetime-only sales. IIE Transactions 27, 1995, pp. 618624

[28] Arcelus, FJ., Srinivasan, G.: Ordering policies under one-time-only discount and price sensitive demand. IIE Transactions 30, 1998, pp. 1057-1064
[29] Arcelus, FJ, Shah, N. H., Srinivasan, G.: Retailer's response to special sales: price discount vs. trade credit. The international Journal of Management Science. Omega 29, 2001, pp. 417-428

[30] Ardalan, A.: Optimal ordering policies in response to a sale. IIE Transactions 20, 1998, pp.292-294

[31] Sterman, J. D.: 'Business Dynamics: Systems Thinking and Modeling for a Complex World', NY: McGraw-Hill Higher Education, 2000

[32] Campuzano Bolarín, F., Mcdonnel Ros, L.: Reducing the Impact of Demand Process Variability within a Multi-Echelon Supply Chain.The Icfai Journal of Supply Chain Management, Vol. V, No. 2, 2008c, pp. 7-21

[33] Silver, Edward A, Pyke, David F., Peterson, Rein: Inventory Management and Production Planning and Scheduling. Wiley, 1998

[34] Web Page: http://www.mapa.es/es/estadistica/pags/ preciosorigendestino/productos.asp 